\title{
Impact of macroeconomic announcements on implied volatility slope of SPX options and VIX is
}

\author{
Mustafa Onan ${ }^{\mathrm{a}, 1}$, Aslihan Salih ${ }^{\mathrm{b}, 2}$, Burze Yasar $^{\mathrm{b}, *}$ \\ ${ }^{a}$ Turkish Industry and Business Association, Mesrutiyet Cad. No: 46 Tepebasi, Istanbul, Turkey \\ ${ }^{\mathrm{b}}$ Bilkent University, Bilkent Üniversitesi, Ankara, Turkey
}

\section{A R T I C L E I N F O}

\section{Article history:}

Received 25 April 2014

Accepted 18 July 2014

Available online 27 July 2014

\section{JEL classification:}

G120

G130

G140

G190

Keywords:

Volatility skews

Slope

S\&P 500 index options

VIX

Macroeconomic announcements

\section{A B S T R A C T}

This paper examines the impact of macroeconomic announcements on the high-frequency behavior of the observed implied volatility skew of S\&P 500 index options and VIX. We document that macroeconomic announcements affect VIX significantly and slope at a lesser extent. We also find evidence that good and bad announcements significantly and asymmetrically change implied volatility slope and VIX.

(C) 2014 Elsevier Inc. All rights reserved.

\section{Introduction}

The Black-Scholes Option Pricing Model presumes that for the same underlying asset, the implied volatilities shall be constant in the same maturity category across different strike prices. However,

\footnotetext{
The views expressed in this paper are those of the author and do not necessarily reflect those of the Turkish Industry and Business Association.

* Corresponding author. Tel.: +90 312290 1778; fax: +90 3122664127.

E-mail addresses: monan@tusiad.org (M. Onan), asalih@bilkent.edu.tr (A. Salih), burze@bilkent.edu.tr (B. Yasar).

1 Tel.: +90 212249 1929; fax: +90 2122491350 .

2 Tel.: +90 312290 2047; fax: +90 3122664127.
} 
empirical literature documents that options on the same underlying with the same maturity dates have different implied volatilities across different strike prices. This anomaly is known as the volatility skew and takes the shape of a smile or a smirk depending on the instrument. Option traders and financial analysts closely monitor the volatility skew as they believe that it carries important information regarding the market structure and the risk aversion of the participants in the market. This paper examines the impact of macroeconomic announcements on the observed implied volatility skew of S\&P 500 index options and VIX in a high-frequency setting.

There have been various studies that investigate the effects of macroeconomic news on financial markets but not in the context of implied volatility skew. Ederington and Lee (1996) are the first to study the impact of macroeconomic announcements on option implied volatility of Tbonds and foreign exchange. Kearney and Lombra (2004) find a significant positive relation between the CBOE volatility index, VIX, and unanticipated changes in employment, but not inflation. Baba and Sakurai (2011) investigate whether macroeconomic variables are leading indicators of regime shifts in the VIX and find that term spreads predict the shift from tranquil to the turmoil regime. Füss et al. (2011) focus only on Gross Domestic Product, Producer Price Index and Consumer Price Index announcements and find that VIX drops on announcement days. This study covers a larger range of macroeconomic announcements and is able to observe the intraday behavior of VIX.

A related strand of literature investigates the effects of monetary policy on stock returns and volatility. Chen and Clements (2007) and Vähämaa and Äijö (2011) investigate the behavior of VIX around US monetary policy announcements and find that implied volatility generally decreases after FOMC meetings. Gospodinov and Jamali (2012) conduct a monthly analysis of the relation between Federal funds rate surprises and implied volatility and volatility risk premium controlling for non-farm payroll employment, consumer price inflation and industrial production announcements. They find that surprises in Fed funds rates and both inflation and industrial growth affect VIX significantly in monthly regressions. Rosa (2011) investigates the effects of Fed's monetary surprises on US stock and volatility indices in a high frequency setting. He finds that the surprise change to the current target federal funds rate significantly affects all indices and the surprise component of Fed's statements affect all but VIX.

This study analyzes the effect of 23 macro announcements, grouped under categories of inflation, investment, employment, real activity and forward-looking, on 2006 high-frequency behavior of VIX and slope of S\&P 500 index options. We also analyze the surprises contained in the announcements by computing the difference between the announced and expected figures. We find that macroeconomic announcement impact is statistically significant on VIX for almost every announcement category and at a lesser extent on slope. To study the asymmetric volatility we further categorize information contained in macroeconomic announcements as good or bad. We find evidence that good and bad announcements asymmetrically affect slope of implied volatility smirk of S\&P 500 Index options and VIX.

The remainder of the paper is organized as follows. Section 2 describes the data and variable construction. Section 3 presents the results of the analysis of the effects of macro announcements on implied volatility skews and VIX. Section 4 concludes.

\section{Data and variable construction}

The data consists of tick-by-tick data of S\&P 500 Index (SPX) option contracts and is obtained from Berkeley Options Database for a total of 250 trading days in $2006 .{ }^{3}$ The dataset is derived from the Market Data Report (MDR file) of the Chicago Board Options Exchange (CBOE) and includes timestamped (in seconds) option trades and quotes (options of all strikes and maturities) including expiration date, put - call code, exercise price, bid and ask prices and contemporaneous price of the underlying S\&P 500 Index. Daily SPX dividend yields and U.S. T-Bill Secondary Market Rates are obtained from the DataStream database. For implied volatility calculations, we use 1-month, 3-month, 6-month, and 1-year

\footnotetext{
${ }^{3}$ Sample data does not coincide with US financial crisis of 2007-2009.
} 
Table 1

Macroeconomic announcements.

\begin{tabular}{|c|c|c|c|c|c|}
\hline Macroeconomic announcement & Time & Source & Frequency & Good & Bad \\
\hline \multicolumn{6}{|l|}{ Employment } \\
\hline ADP employment change & $8: 15$ & ADP & Five times & - & + \\
\hline Unemployment rate & $8: 30$ & BLS & Monthly & - & + \\
\hline Initial jobless claims & $8: 30$ & UDL & Weekly & - & + \\
\hline \multicolumn{6}{|l|}{ Inflation } \\
\hline Consumer price index & $8: 30$ & BLS & Monthly & - & + \\
\hline Unit labor costs & $8: 30$ & BLS & Eight times & - & + \\
\hline GDP price index & $8: 30$ & BEA & Monthly & - & + \\
\hline Producer price index & $8: 30$ & BLS & Monthly & - & + \\
\hline \multicolumn{6}{|l|}{ Forward-looking } \\
\hline Chicago purchasing manager & $10: 00$ & ISM & Monthly & + & - \\
\hline Consumer confidence & 10:00 & $\mathrm{CB}$ & Monthly & + & - \\
\hline IBD/TIPP economic optimism & $10: 00$ & IBD & Six times & + & - \\
\hline Philadelphia Fed. & $12: 00$ & FRBP & Monthly & + & - \\
\hline Index of leading indicators & $10: 00$ & $\mathrm{CB}$ & Monthly & + & - \\
\hline Housing starts & $8: 30$ & $\mathrm{BC}$ & Monthly & + & - \\
\hline \multicolumn{6}{|l|}{ Investment } \\
\hline Durable goods orders* & $8: 30$ & $\mathrm{BC}$ & Monthly & + & - \\
\hline Factory orders & $10: 00$ & $\mathrm{BC}$ & Monthly & + & - \\
\hline Construction spending & $10: 00$ & $\mathrm{BC}$ & Monthly & + & - \\
\hline Business inventories & $10: 00$ & $\mathrm{BC}$ & Monthly & - & + \\
\hline Wholesale inventories & $10: 00$ & $\mathrm{BC}$ & Monthly & - & + \\
\hline \multicolumn{6}{|l|}{ Real activity } \\
\hline Personal income/spending & $8: 30$ & BEA & Monthly & + & - \\
\hline Retail sales less autos & $8: 30$ & $\mathrm{BC}$ & Monthly & + & - \\
\hline Capacity utilization/industrial production & $9: 15$ & FRB & Monthly & + & - \\
\hline \multicolumn{6}{|l|}{ Other } \\
\hline Existing home sales & $8: 30$ & NAR & Monthly & + & - \\
\hline New home sales & $10: 00$ & $\mathrm{BC}$ & Monthly & + & - \\
\hline
\end{tabular}

Table lists the macroeconomic announcements used in this study along with the category, timing in EST, source, frequency. We separate good and bad announcements by comparing realized and expected numbers. If the realized value is higher than the expected value in surveys and stimulates economic growth then the news is classified as good. If the news implies economic slowdown or higher inflation then it is classified as bad. Abbreviations are Investors Business Daily (IBD), Automatic Data Processing (ADP), Federal Reserve Board (FRB), Bureau of Labor and Statistics (BLS), Bureau of Economic Analysis (BEA), Bureau of the Census (BC), Conference Board (CB), US. Department of Labor (UDL), Institute for Supply Management (ISM), Federal Reserve Bank of Philadelphia (FRBP) and National Association of Realtors (NAR).

* When there is also a GDP announcement that day, the durable goods orders announcement is made at 10:00 AM.

nominal U.S. T-Bill Secondary Market Rates and apply cubic spline polynomial interpolation to match maturity dates of options.

Tick by tick options data is filtered based on maturity, no-arbitrage lower option boundaries and for obvious reporting errors and outliers. In order to avoid implied volatilities that are likely to be measured with error, only options with bid prices greater than zero are used. ${ }^{4}$ Put-Call parity violations are not filtered as they might contain evidence related to the trading activity of informed traders (Cremers and Weinbaum, 2010). We include options that have maturities between 15 and 45 trading days since these are the most liquid options. This study does not include options that have maturities shorter than 15 days, as shorter term options have relatively small time premiums and are substantially unreliable when calculating option implied volatilities (Dumas et al., 1998).

The macroeconomic announcement timings, realizations and survey expectations are obtained from Bloomberg. Most of the announcements are monthly but initial jobless claims announcement is weekly and we also have a number of quarterly announcements. We group macroeconomic

\footnotetext{
${ }^{4}$ In a same manner, but a bit different approach, some authors use options with bid-ask midpoints higher than 0.125 or 0.25 .
} 
announcements under five categories: inflation, investment, employment, real activity and forwardlooking.

Macroeconomic announcements are also categorized as good and bad news according to their surprise component as in Bauwens et al. (2005). For a macroeconomic figure, if the realized value is higher than the expected value in surveys and stimulates economic growth then the news is classified as good. If the news implies economic slowdown then it is classified as bad. If the figure is an inflation related news and the actual is higher than expected then the news is classified as bad news. Table 1 provides the frequency, source, timing and categorization for the list of macroeconomic announcements.

The surprise component is defined as the difference between the announced figure and survey expectations. Surprises are assumed to be stochastic since they are related to the incorrect anticipation by the market participants. To allow for meaningful comparisons of coefficients across different news categories, we standardize news by the standard deviation of the surprise component for different announcements as in Andersen et al. (2007). The standardized news for announcement $k$ at time $t$, $S_{k, t}$, is defined as follows:

$$
S_{k, t}=\frac{\text { Actual }_{k, t}-\text { Expectation }_{k, t}}{\hat{\sigma}_{k}}
$$

where Actual $_{k, t}$ refers to the announced value and Expectation ${ }_{k, t}$ refers to the market's expectation, for macro fundamental $k$ at time $t$. $\hat{\sigma}_{k}$ refers to the sample standard deviation of the surprise component, the difference between Actual $_{k, t}$ and Expectation $_{k, t}$ is constant for any macro fundamental $k$.

\subsection{Data filtering and analysis}

One of the problems of working with high frequency data is arrival of market ticks at random time. Regular time-series econometric tools which frequently use backward operators cannot be applied to irregularly spaced or inhomogeneous time series (Gençay et al., 2001). Traditional approach to this problem is to equally space time-series data and work with time bars. In order to homogenize time series data, high-frequency finance literature uses interpolation and aggregation. Aït-Sahalia et al. (2005) note that sampling too frequently may not be optimal in the presence of market microstructure noise. Moreover, our trade data is not as frequent as quote data. Therefore, we choose subsampling frequency as thirty-min intervals.

Implied volatility calculations are conducted using Black and Scholes option pricing formula. We first calculate implied volatilities for the European-style S\&P 500 index options for each moneyness category. Options are grouped in moneyness categories according to their deltas. A call option with $\Delta_{\text {call }}=0.5$ is treated as an ATM call option. Similarly, a put option with $\Delta_{p u t}=-0.5$ is treated as an ATM put option. Although these options are not exactly ATM, they are very close to being ATM (Yan, 2011).

The slope measure is defined as the difference between ATM puts and calls as in Yan (2011):

$$
S=v_{\text {put }}^{\text {imp }}(-0.5)-v_{\text {call }}^{\text {imp }}(0.5)
$$

where implied volatilities of put and call options with deltas equal to $\Delta_{\text {put }}$ and $\Delta_{\text {call }}$ are denoted as $v_{\text {put }}^{\text {imp }}\left(\Delta_{\text {call }}\right)$ and $v_{\text {put }}^{\text {imp }}\left(\Delta_{\text {put }}\right)$ respectively. We standardize slope by dividing it to daily realized volatility to control for the fluctuations in slope related to the level of volatility.

\subsection{Momentum and liquidity effects}

According to market momentum hypothesis if past returns are positive, investors expect future stock returns to be positive and they will tend to buy call options on the market index. Similarly if past returns are negative, investors will buy put options. High demand for call (put) options will create an upward pressure on call (put) prices. Amin et al. (2004) do find that option prices depend on stock market momentum. They find that when stock returns decline, call-smile more than doubles and put smile more than triples. The effect is visible for at the money options but higher for out of the 
Table 2

Summary statistics.

\begin{tabular}{lllll}
\hline & Slope & Std. slope & IV & VIX \\
\hline Min & -0.094 & -24.467 & 0.021 & 9.41 \\
Mean & 0 & 0.081 & 0.116 & 13.544 \\
Max & 0.103 & 22.565 & 0.198 & 23.43 \\
Std. Dev. & 0.011 & 2.196 & 0.023 & 2.82 \\
Skewness & 0.958 & 1.422 & 0.871 & 0.969 \\
Kurtosis & 17.306 & 26.031 & 0.808 & 0.366 \\
\hline
\end{tabular}

Table lists the summary statistics for our variables. Slope is slope of implied volatility skew of SPX options calculated as the difference between ATM calls and puts during 2006. Std. Slope is Slope divided by daily realized volatility. IV is the average of ATM call and put implied volatilities. VIX is the CBOE's volatility index for the S\&P 500 index return.

money options. They conclude that even though market momentum seems to affect the volatility smiles, it does not completely explain volatility smiles. Therefore we control for momentum or past stock return effects using lagged thirty-min returns. Literature also proposes liquidity as a possible determinant of implied volatility skew. Since we are using ATM options, liquidity is less of an issue in our analysis. Table 2 presents the summary statistics for our variables.

\section{Empirical results}

The objective of the empirical analysis is to analyze whether macroeconomic announcements affect standardized implied volatility slope of S\&P 500 options and VIX. We start the analysis by conducting the Augmented Dickey-Fuller stationarity tests on our variables. We are able to reject the existence of a unit root for standardized slope and first difference of VIX. Observation of the ACF reveals that standardized slope is highly auto-correlated and decays slowly for thirty-min data. Therefore we test for long memory in slope using the range over standard deviation (R/S statistic) and GPH test. Both methods confirm that long memory exists in the time-series of standardized slope. In this respect, we use fractional autoregressive integrated moving average (FARIMA) process to model the short run dynamics and long range dependence in time series of standardized slope simultaneously.

We first estimate the following regression to measure the response of standardized slope to macroeconomic announcement categories:

$$
\text { StdSlope }_{t}=\alpha+\omega R_{t}+\sum_{k} \sum_{p} \beta_{k, p} D_{k(t-p)}+e_{t}
$$

where Std Slope $e_{t}$ is defined as the ratio of the difference between ATM put and call implied volatilities to daily realized volatility. The dependent variable is the residual from FARIMA model of standardized slope. We examine the intraday changes in standardized slope using thirty-min time intervals. For each time bar we calculate slope using the ATM call and put trades that are closest to the end of thirty-min time intervals. $R_{t}$ is the index return computed from time interval $t-16$ to $t-1$ and included as a control variable for the momentum effect. $D_{k, t}$ is a dummy variable that takes one for the thirty-min interval $t$ that includes a macroeconomic announcement that belongs to category $\mathrm{k}$ at time $\mathrm{t}$ and zero otherwise. Since the options market operates in CT, it is not open during macroeconomic announcements made at 8:30 am EST, $D_{k, t}$ takes one for the first thirty-min interval of that day.

Table 3 displays the results of regression in Eq. (5) and show that investment, inflation and real activity announcement categories seem to have an impact on the slope of implied volatility skew of S\&P 500 Index Options. Real activity category announcements seem to increase slope first and then cause a drop in slope in three and a half hours with higher statistical significance. Employment and forward-looking category announcements do not seem to be related to slope, with an exception of forward looking announcements category decreasing slope in three and a half hours only with $10 \%$ statistical significance. Inflation and investment announcement categories point to an increase in risk aversion and increases in slope. Index return variable positively affects standardized slope with a $1 \%$ statistical significant coefficient. This supports finding of Amin et al. (2004) about volatility spread increasing after stock market increases during the period March 1983 to December 1995.

\subsection{Asymmetric news effect}

Research suggests that investors show asymmetric responses to good and bad news. By separating macroeconomic announcements into good and bad news, we try to assess the asymmetric effects on slope with the following analysis:

$$
\text { StdSlope }_{t}=\alpha+\omega R_{t}+\sum_{p} \beta_{p} \text { PosDummy }_{(t-p)}+\sum_{p} \delta_{p} \text { NegDummy }_{(t-p)}+e_{t}
$$

where PosDummy (NegDummy) is a dummy variable that is an aggregation of all good (bad) announcements across all macroeconomic categories. 
Table 3

Impact of macroeconomic announcement categories on slope.

\begin{tabular}{|c|c|c|c|c|c|c|}
\hline & \multicolumn{2}{|l|}{$R_{n}$} & \multicolumn{2}{|c|}{ Employment } & \multicolumn{2}{|c|}{ Forward-looking } \\
\hline & Coefficient & $t$-Value & Coefficient & $t$-Value & Coefficient & $t$-Value \\
\hline$t$ & 17.598 & $2.204^{* *}$ & -0.551 & -1.443 & -0.061 & -0.170 \\
\hline$t-1$ & & & -0.041 & -0.106 & -0.422 & -1.177 \\
\hline$t-2$ & & & 0.120 & 0.314 & -0.201 & -0.561 \\
\hline$t-3$ & & & -0.295 & -0.773 & -0.247 & -0.688 \\
\hline$t-4$ & & & 0.078 & 0.202 & -0.044 & -0.123 \\
\hline$t-5$ & & & -0.558 & -1.447 & 0.579 & 1.637 \\
\hline$t-6$ & & & -0.058 & -0.150 & 0.051 & 0.144 \\
\hline \multirow[t]{2}{*}{$t-7$} & & & 0.550 & 1.428 & -0.585 & $-1.656^{*}$ \\
\hline & \multicolumn{2}{|l|}{ Investment } & \multicolumn{2}{|l|}{ Inflation } & \multicolumn{2}{|l|}{ Real Activity } \\
\hline$t$ & -0.281 & -0.658 & -0.262 & -0.565 & 0.885 & $1.675^{*}$ \\
\hline$t-1$ & 0.604 & 1.416 & 0.700 & 1.509 & -0.165 & -0.312 \\
\hline$t-2$ & -0.188 & -0.440 & 1.030 & $2.219^{* *}$ & -0.725 & -1.371 \\
\hline$t-3$ & -0.512 & -1.199 & -0.454 & -0.978 & 1.005 & $1.901^{*}$ \\
\hline$t-4$ & -0.198 & -0.463 & 0.556 & 1.199 & 0.094 & 0.177 \\
\hline$t-5$ & 0.608 & 1.420 & -0.469 & -1.012 & 0.731 & 1.383 \\
\hline$t-6$ & -0.656 & $-1.532^{* *}$ & 0.077 & 0.165 & 0.425 & 0.804 \\
\hline$t-7$ & 1.078 & 2.518 & 1.365 & $2.944^{* * * *}$ & -1.237 & $-2.340^{* *}$ \\
\hline
\end{tabular}

Table presents the regression results of Std Slope $e_{t}=\alpha+\omega R_{t}+\sum_{k} \sum_{p} \beta_{k, p} D_{k(t-p)}+e_{t}$ where Std Slope $e_{t}$ is slope of implied volatility skew of SPX options calculated as the difference between ATM calls and puts and standardized by daily realized volatility during 2006, $R_{t}$ is the daily S\&P 500 Index return computed on a rolling basis using the last 16 thirty-min time intervals. $D_{k, t}$ is a dummy variable that takes one for the thirty-min interval $t$ that includes a macroeconomic announcement that belongs to category $k$ at time $t$ and zero otherwise. Macroeconomic announcement categories are Employment, Forward-looking, Inflation, Investment and Real Activity. Newey-West correction is used in the regressions.

* Statistical significance at the $10 \%$ level.

** Statistical significance at the $5 \%$ level.

*** Statistical significance at the $1 \%$ level.

Table 4

Impact of good and bad announcements on slope.

\begin{tabular}{|c|c|c|c|c|}
\hline & \multicolumn{2}{|c|}{ Announcement dummy } & \multicolumn{2}{|c|}{ Announcement surprise } \\
\hline & Coefficient & $t$-Value & Coefficient & $t$-Value \\
\hline$\alpha$ & 0.011 & 0.0519 & -0.0296 & -0.5749 \\
\hline$R_{t}$ & 17.7335 & $7.9844^{* *}$ & 17.3929 & 2.1799 \\
\hline \multicolumn{5}{|c|}{ Good news } \\
\hline$t$ & -0.4084 & 0.3171 & 0.1632 & 0.7732 \\
\hline$t-1$ & -0.1435 & 0.3172 & 0.048 & 0.2273 \\
\hline$t-2$ & -0.8406 & $0.3173^{* * *}$ & -0.3422 & -1.6217 \\
\hline \multicolumn{5}{|c|}{ Bad news } \\
\hline$t$ & -0.1002 & 0.3501 & -0.2593 & -1.2266 \\
\hline$t-1$ & 0.3174 & 0.3501 & 0.4547 & $2.151^{\text {*** }}$ \\
\hline$t-2$ & 0.5546 & 0.35 & 0.4829 & $2.2852^{* *}$ \\
\hline
\end{tabular}

Table presents the results of StdSlope $e_{t}=\alpha+\omega R_{t}+\sum_{p} \beta_{p}$ PosDummy $_{(t-p)}+\sum_{p} \delta_{p}$ NegDummy $_{(t-p)}+e_{t}$ in the first two columns and StdSlope $e_{t}=\alpha+\omega R_{t}+\sum_{p} \beta_{p}$ PosSurprise $_{(t-p)}+\sum_{p} \delta_{p}$ NegSurprise $_{(t-p)}+e_{t}$ in the last two columns. Std Slope $e_{t}$ is slope of implied volatility skew of SPX options calculated as the difference between ATM calls and puts and standardized by daily realized volatility during 2006, $R_{t}$ is the daily S\&P 500 Index return computed on a rolling basis using the 16 thirty-min time intervals. PosDummy (NegDummy $_{t}$ ) is a dummy variable that is an aggregation of all good (bad) macroeconomic announcements. PosSurprise ( NegSurprise $_{t}$ ) is sum of standardized surprises for good (bad) announcements Newey-West correction is used in the regressions.

"Statistical significance at the $10 \%$ level.

** Statistical significance at the $5 \%$ level.

${ }^{* * *}$ Statistical significance at the $1 \%$ level. 
Table 5

Impact of macroeconomic announcements on VIX.

\begin{tabular}{|c|c|c|c|c|c|c|}
\hline & \multicolumn{2}{|l|}{$R_{t}$} & \multicolumn{2}{|c|}{ Employment } & \multicolumn{2}{|c|}{ Forward-looking } \\
\hline & Coeff. & $t$-Value & Coeff. & $t$-Value & Coeff. & $t$-Value \\
\hline$t$ & -2.0834 & $-11.0325^{* * *}$ & -0.0458 & $-2.9513^{* * * *}$ & -0.0403 & $-2.5142^{* *}$ \\
\hline$t-1$ & & & -0.0462 & $-2.9603^{* * *}$ & 0.0178 & 1.1148 \\
\hline \multirow[t]{2}{*}{$t-2$} & & & -0.0019 & $-0.1186^{* * *}$ & 0.0054 & 0.3401 \\
\hline & \multicolumn{2}{|c|}{ Investment } & \multicolumn{2}{|l|}{ Inflation } & \multicolumn{2}{|c|}{ Real activity } \\
\hline$t$ & 0.0472 & $2.8888^{* * *}$ & -0.0843 & $-4.2462^{* * * *}$ & 0.0097 & 0.4543 \\
\hline$t-1$ & 0.0176 & 1.077 & 0.0083 & 0.4248 & -0.0079 & -0.3686 \\
\hline$t-2$ & -0.0028 & -0.1742 & -0.0214 & -1.0916 & 0.0207 & 0.965 \\
\hline
\end{tabular}

Table presents the results of $\Delta V I X_{t}=\alpha+\omega R_{t}+\sum_{k} \sum_{p} \beta_{k, p} D_{k(t-p)}+e_{t}$ where the dependent variable is the first difference of VIX. $R_{t}$ is the daily S\&P 500 Index return computed on a rolling basis using the last 16 thirty minute time-intervals. $D_{k, t}$ is a dummy variable that takes one for the thirty-minute interval $t$ that includes a macroeconomic announcement that belongs to category $\mathrm{k}$ at time $t$ and zero otherwise. Macroeconomic announcement categories are employment, forward-looking, inflation, investment and real activity. Newey-West correction is used in the regressions.

"Statistical significance at the $10 \%$ level.

** Statistical significance at the $5 \%$ level.

**** Statistical significance at the $1 \%$ level.

Table 6

Impact of good and bad announcements on VIX.

\begin{tabular}{lcccc}
\hline & \multicolumn{2}{c}{ Announcement dummy } & & \multicolumn{2}{c}{ Announcement surprise } \\
\cline { 2 - 3 } & Coefficient & & Coefficient & $t$-Value \\
\cline { 1 - 2 }$\alpha$ & 0.0014 & 1.1084 & 0.0014 & 1.1606 \\
$R_{t}$ & -2.0098 & $-10.4614^{* * *}$ & -2.0279 & $-10.5483^{* * *}$ \\
Good news & & & & $-3.4335^{* * *}$ \\
$t$ & -0.0734 & $-5.723^{* * *}$ & -0.0341 & -0.0119 \\
$t-1$ & 0.0095 & 0.7426 & -0.0001 & -0.6368 \\
$t-2$ & -0.0032 & -0.2486 & -0.0063 & -0.116 \\
Bad news & & & & -1.4956 \\
$t$ & 0.032 & $2.7207^{* * *}$ & -0.0011 & $2.0464^{* *}$ \\
$t-1$ & -0.0193 & -1.6398 & -0.0143 & 0.0195 \\
$t-2$ & 0.0143 & 1.2175 & & \\
\hline
\end{tabular}

Table presents the results of the regression $\Delta V I X_{t}=\alpha+\omega R_{t}+\sum_{p} \beta_{p}$ PosDummy $_{(t-p)}+\sum_{p} \delta_{p}$ NegDummy $_{(t-p)}+e_{t}$ and equation 12 where the dependent variable is the first difference of VIX. $R_{t}$ is the daily S\&P 500 Index return computed on a rolling basis using the last 16 thirty-min time intervals. $\mathrm{Pos}_{t}\left(\mathrm{Neg}_{t}\right)$ is a dummy variable that is an aggregation of all good (bad) macroeconomic announcements. Macroeconomic announcement categories are Employment, Forward-looking, Inflation, Investment and Real Activity. Newey-West correction is used in the regressions.

"Statistical significance at the $10 \%$ level.

** Statistical significance at the $5 \%$ level.

**** Statistical significance at the $1 \%$ level.

The impact of macroeconomic variables also depends on the surprise created by the announcement. Therefore we test for the impact of good and bad surprises by creating two separate variables. Taking into consideration the multicollinearity problem (news surprises have values at the announcement time while they are zero at other times), we sum standardized surprises across all different categories for good and bad announcements. The following regression estimates the extent to which the surprise component of good and bad announcements impact slope.

$$
\text { Std Slope }_{t}=\alpha+\omega R_{t}+\sum_{p} \beta_{p} \text { PosSurp }_{(t-p)}+\sum_{p} \delta_{p} \operatorname{NegSurp}_{(t-p)}+e_{t}
$$

We expect that changes in slope of implied volatility skew will vary for good and bad news as investor risk aversion changes with respect to the nature of the surprise. We hypothesize that good surprises will decrease risk aversion and slope, whereas bad news will have an increasing impact on both.

Table 4 displays the results of regression in Eqs. (6) and (7) and show that good and bad news affect the slope of implied volatility skew of S\&P 500 Index Options differently. Table presents the results of regressing residuals from the FARIMA modeled standardized slope on one day return and good and bad announcement dummies up to two lags using thirty-min time bars. Good announcement dummy decreases slope by 0.841 at $1 \%$ significance level at the second lag. Bad announcement dummy 
does not affect slope significantly. Table also presents the results of a similar regression on the surprise component of the announcements. Bad surprises increase slope statistically significantly at $5 \%$ level at both first and second lags. Good surprises do not seem to affect slope significantly. One day return is positively and statistically significantly related to slope.

\subsection{VIX and macroeconomic announcements}

Literature accepts VIX as a good proxy for future index volatility. We aim to analyze the changes of VIX in response to macroeconomic announcements. We first analyze the effects of macroeconomic announcements on the first difference of VIX and then investigate whether there is asymmetric news impact. Table 5 presents the results of regressing first difference of VIX on macroeconomic announcement categories controlling for momentum effects. All the regressors except for real activity announcement affect VIX significantly. Employment, forward-looking and inflation announcements are negatively related with changes in VIX, pointing to a resolution of uncertainty with these announcements. The drop in VIX in response to inflation related news is in line with Füss et al. (2011). Unlike Kearney and Lombra (2004), we also find that inflation news affect VIX significantly. The differences in our results may stem from the fact that our analysis is at high frequency. Investment is positively related to VIX at $1 \%$ significance level suggesting an increase in uncertainty with this category of announcements. When we analyze Table 6 that shows the effects of good and bad announcements on VIX separately, we see that good news decrease and negative news increase VIX statistically significantly at $1 \%$ level in line with literature about asymmetric news effect on volatility.

\section{Conclusion}

This paper examines the high frequency characteristics of S\&P 500 index options' implied volatility skew and VIX. Slope of implied volatility skew is a good proxy for jump risk and investor risk aversion. VIX is a good measure of both market risk and investor 'fear gauge'. In an attempt to explain changes in these parameters proxied by slope and VIX, we examine a broad range of macroeconomic announcements. Results document a statistically significant relation between VIX and macroeconomic announcements even after controlling for liquidity, volatility and momentum effects. The effects of macroeconomic announcements on slope are more gradual compared to responses of VIX. We further categorize announcements into good and bad news to investigate whether there is any asymmetric news effect. We do find evidence that good and bad announcements asymmetrically change slope of implied volatility skew of S\&P 500 Index options and VIX.

A clearer comprehension about the factors that affect the slope is important for developing new option pricing models and devising proper hedging and investment strategies. Our results justify why traders shall closely monitor slope to understand how jump risk and risk aversion are evolving during a trading day.

\section{Acknowledgment}

We would like to acknowledge financial support from the Scientific and Technological Research Council of Turkey (TUBITAK).

\section{References}

Aït-Sahalia, Y., Mykland, P.A., Zhang, L., 2005. How often to sample a continuous-time process in the presence of market microstructure noise. Rev. Financ. Stud. 18 (2), 351-416.

Amin, K., Coval, J.D., Seyhun, H.N., 2004. Index option prices and stock market momentum*. J. Business 77 (4), 835-874.

Andersen, T.G., Bollerslev, T., Diebold, F.X., Vega, C., 2007. Real-time price discovery in global stock, bond and foreign exchange markets. J. Int. Econ. 73 (2), 251-277.

Baba, N., Sakurai, Y., 2011. Predicting regime switches in the VIX index with macroeconomic variables. Appl. Econ. Lett. 18 (15), 1415-1419.

Bauwens, L., Ben Omrane, W., Giot, P., 2005. News announcements, market activity and volatility in the euro/dollar foreign exchange market. J. Int. Money Finance 24 (7), 1108-1125.

Chen, E.T.J., Clements, A., 2007. S\&P 500 implied volatility and monetary policy announcements. Finance Res. Lett. 4 (4), $227-$ 232.

Cremers, M., Weinbaum, D., 2010. Deviations from put-call parity and stock return predictability. J. Financ. Quant. Anal. 45 (2), 335.

Dumas, B., Fleming, J., Whaley, R.E., 1998. Implied volatility functions: empirical tests. J. Finance 53 (6), 2059-2106.

Ederington, L.H., Lee, J.H., 1996. The creation and resolution of market uncertainty: the impact of information releases on implied volatility. J. Financ. Quant. Anal. 31 (4).

Füss, R., Mager, F., Wohlenberg, H., Zhao, L., 2011. The impact of macroeconomic announcements on implied volatility. Appl. Financ. Econ. 21 (21), 1571-1580. 
Gençay, R., Dacorogna, M., Muller, U.A., Pictet, O., Olsen, R., 2001. An Introduction to High-frequency Finance. Access Online via Elsevier.

Gospodinov, N., Jamali, I., 2012. The effects of Federal funds rate surprises on S\&P 500 volatility and volatility risk premium. J. Emp. Finance 19 (4), 497-510.

Kearney, A.A., Lombra, R.E., 2004. Stock market volatility, the news, and monetary policy. J. Econ. Finance 28 (2), $252-259$.

Rosa, C., 2011. Words that shake traders: the stock market's reaction to central bank communication in real time. J. Emp. Finance 18 (5), 915-934.

Vähämaa, S., Äijö, J., 2011. The Fed's policy decisions and implied volatility. J. Futures Markets 31 (10), 995-1010.

Yan, S., 2011. Jump risk, stock returns, and slope of implied volatility smile. Journal of Financial Economics 99 (1), $216-233$. 